\title{
Factors Associated with Risky Sexual Behavior among Jigjiga University Students in Jigjiga Ethiopia, 2018
}

\author{
Meka Kedir Jibril1 ${ }^{*}$, Meron Kibru ${ }^{2}$ \\ ${ }^{1}$ Department of Nursing, Psychiatric Unit, College of Medicine and Health Sciences, Jigjiga University, Jigjiga, Ethiopia \\ ${ }^{2}$ Department of Midwifery, College of Medicine and Health Sciences, Jigjiga University, Jigjiga, Ethiopia \\ Email: j.meka19@yahoo.com, meronkibru@gmail.com
}

How to cite this paper: Jibril, M.K. and Kibru, M. (2020) Factors Associated with Risky Sexual Behavior among Jigjiga University Students in Jigjiga Ethiopia, 2018. Open Access Library Journal, 7: e6768. https://doi.org/10.4236/oalib.1106768

Received: September 1, 2020

Accepted: October 17, 2020

Published: October 20, 2020

Copyright $\odot 2020$ by author(s) and Open Access Library Inc.

This work is licensed under the Creative Commons Attribution International License (CC BY 4.0).

http://creativecommons.org/licenses/by/4.0/ (c) (i) Open Access

\begin{abstract}
Background: Adolescents and youths are known to be an adventurous group, and often engage in risky behaviors such as smoking, drinking alcohol, using drugs, and early unprotected sexual activity. University students are viewed as being at higher risks to acquire STI or HIV infection and they are categorized under the most at risk population segments due to their inclination to be engaged in risky sexual behavior. Methods: Institutional based descriptive cross-sectional study design was conducted from May 2018 to June 2018 among Jigjiga University students in Jigjiga, Ethiopia. A total of 403 study participants were included in the study. Pre-tested structured questionnaire was used for interviewing the study participants. The collected data was coded and entered in to EPI-INFO version 3.5.3 software and analyzed by using SPSS version 20 . Binary logit econometric model was employed. The association between variables was analyzed using Bivariate and multivariate logistic regression and the level of significance of association was determined at $\mathrm{P}$-value $<0.05$. Results: A total of 403 (out of which 260 (65\%) were male and 143(35\%) female) university students participated in this study with $97 \%$ response rate. The result indicates that, age $[\mathrm{AOR}=3.82,95 \% \mathrm{CI},(2.28,9.41)]$, active in my faith/religion $[\mathrm{AOR}=3.68,95 \% \mathrm{CI},(1.344,10.115)]$, contraceptive use [AOR $=6.38,95 \% \mathrm{CI}(3.96,10.27)]$, condom use $[\mathrm{AOR}=6.38,95 \% \mathrm{CI}(3.96$, $10.27)]$, peer pressure $[\mathrm{AOR}=14.52,95 \% \mathrm{CI}(4.702,44.891)]$, tobacco consumption[AOR $=3.19195 \% \mathrm{CI}(1.83,5.54)]$ and alcohol use $[1.64,95 \% \mathrm{CI}$ $(1.39,2.06)]$ were the commonest factors associated with risky sexual behavior. Conclusion: The study revealed that being too young in terms of age, not believing actively in faith/religion practice, lack of contraceptive method, not using condom, peer pressure, tobacco use and drinking alcohol were factors in the study that can lead youths to engage in risky sexual behaviors.
\end{abstract}




\section{Subject Areas}

Epidemiology, HIV, Health Policy, Psychiatry \& Psychology, Public Health

\section{Keywords}

Peer Pressure, Sexual Behavior, Substance Use, Youths

\section{Introduction}

One of the most important commitments a country can make for future economic, social, and political progress and stability, therefore, is to address the sexual and reproductive health needs of this population group [1]. Adolescents are known to be an adventurous group, and often engage in risky behaviors such as smoking, drinking alcohol, using drugs, and early unprotected sexual activity [2].

Adolescence and adulthood are critical target groups for sexual behavioral change programs. While sexual abstinence is the preferred method of HIV prevention among this group of people, it is not practical for many of individuals. Therefore, consistent and correct condom use is a reasonable method of preventing the transmission and acquiring HIV and other sexually transmitted infections [3].

Risky sexual behaviors are defined as behaviors which increase the chance of contracting or transmitting disease or increase the chance of occurrence of unwanted pregnancy. Those include having more than one sexual partner, changing sexual partners frequently, having sex without condom, not using contraceptive [4].

Most adults are educated about risky sexual behaviors. However, unsafe sexual practices are still occurring with sufficient frequency so that sexually transmitted diseases and unwanted pregnancy remain significant public health concerns. The WHO reported in 2009 that unsafe sex was second among the top ten first factors in the global burden of all diseases caused globally [5].

Studies have found that the highest group infected with HIV is the age group of 15 to 24 years where most of the university student's fall and these findings point to a need for investigation of sexual behavior in universities as a matter of priority [6]. Risky sexual activities could result in varying problems ranging from unwanted pregnancy, to abortion, to contacting STIs including HIV, and even to death. In fact, it is estimated that one-half of all HIV infections occur among people younger than 25 years [7].

University/college students are viewed as being at higher risks to acquire STI or HIV infection and they are categorized under the most at risk population segments (MARPS) due to their inclination to be engaged in risky sexual behavior and their sense of non-vulnerability [8]. Despite high level of knowledge, university students involve in unprotected sex with casual partners and fail to 
recognize that they are at risk of HIV infection [9].

A number of studies have investigated the consequences of sexual behavior especially among university students. Further to these, there is sufficient knowledge of these consequences based on science and medicine. Sexually Transmitted Diseases (STDs), including human immuno-deficiency virus (HIV) infections, constitute a major reproductive health burden for sexually-active individuals. Consequences of STDs include genital and other cancers, pelvic inflammatory disease, ectopic pregnancy, infertility, and adverse outcomes of pregnancy including pre-term delivery and low birth weight [10].

Other known consequences of irresponsible sexual behavior include unwanted pregnancies, abortion, social stigma, dropping from schools etc., which often result into a serious damage to the victims' self-esteem. This in turn negatively impacts on their opportunities for individual growth as well as the growth of their families [11].

The study done in Greece shows that a high rate of tobacco, alcohol, and drug consumption among youth is present [12]. Water pipe smoking, which is perceived as less toxic than cigarettes, is mostly carried out in cases of stress or for mere pleasure [13]. Alcohol consumption [14], particularly in the case of psychological problems is also high among university students [15]. Cigarette smoking, $19 \%$ of the sample was made of current smokers while $23 \%$ were current water pipe smokers. Private universities included significantly higher rates for both types of smoking (p, 0.001). Moreover, 33.5\% declared consuming alcohol; with higher rates in private versus public universities (p, 0.001) [16]. Study done in Kwazulu Natal, South Africa shows that Violence in relationships, the fear of being discarded by a partner and the need to prove manhood/womanhood instigates students' sexual risk behavior. And also argues that students arrived at university with little financial support for food and fees, and lack of disposable income encourages risky behavior [17].

There are three schools of thought regarding the role of self-esteem and its association with sexual behavior. One school suggests that there is a relationship between low self-esteem and engaging in high risk sexual behaviors (i.e. if one has low self-esteem, he/she is more likely to engage in high-risk sexual behaviors such as unprotected intercourse [18]. Another school suggests that there is a relationship between high self-esteem and high-risk sexual behaviors (i.e. if one has high self-esteem, he/she is more likely to feel invincible and thus feel more free to engage in high-risk sexual behaviours) [19]. The last school suggests that there is no association between self-esteem and sexual behavior [20]. Adolescents who are isolated or rejected by peer group suffer a loss of self-esteem and other emotional distress and at risk of a wide range of risky behavior of which sexual risk is prominent [21].

Study conducted in Delta State Nigeria, indicated that emotional intelligence, self-esteem, media and religiosity made a significantly contribution of about $43 \%$ to the prediction of adolescents' risky sexual behavior [22]. Of study done in 
MizanTepi University and Mada Walabu University participants (sexually active students) gave falling in love as a reason to initiate sex is $40 \%$ and $53 \%$ respectively [23] [24].

The vision of ministry of education (MOE) is " building an education and training system which assures quality and equality of education by the year 2020 that aims at producing competent citizens", reducing risky sexual behavior and promoting condom utilization in university students is essential to achieve the mission and vision [25].

The present study would tend to contribute to fill the gap of determinants of risky sexual behavior in this university and would be used as an input to policy makers in achieving of mission and vision of Ministry of health, Ministry of Education and the country at all [26].

In recent years, studies have been conducted to identify the prevalence among students with risky sexual behavior. But, few cases of factors associated for risky sexual behavior are known. Therefore, this study was aimed to assess the factors associated with risky sexual behavior, which may support the intervention towards reducing risky sexual behavior among Jigjiga university students.

\section{Methods and Materials}

\subsection{Study Design and Setting}

This Institutional based descriptive cross-sectional study design was conducted by 2018 at Jigjiga University. It is one of the $45^{\text {th }}$ universities in Ethiopia that is located in Somali regional state. It was established in 1999 E.C. The university had five programmes namely; post graduates, regular, evening, weekend and summer. It had eleven colleges. Currently, the university enrolled more than 25,532 with 17,247 males and 8285 females.

\subsection{Sample Size and Sampling Techniques}

Based on, the study of prevalence on risky sexual behaviors among Jigjiga University students; about $44.6 \%$ of the variation of risky sexual behavior among adolescents was accounted. The sample size was calculated by assuming the expected risky sexual behavior among, $44.6 \%, 95 \%$ confidence level, using a simple population formula:

$$
n^{2}=\frac{Z \alpha^{2} p(1-p)}{d^{2}}
$$

where;

$n=$ is the minimum sample size required

$Z=$ standard normal distribution $(Z=1.96)$ with confidence interval of $95 \%$ and $\alpha=0.05$

$P=$ the expected risky sexual behavior among the students is $44.6 \%$; hence, $P$ $=44.6 \%(0.44)$ was used, $d=$ Absolute precision or tolerable margin of error $(d)$ $=5 \%=0.05$ 
The following assumption will be made during determining the sample size

$$
\mathrm{n}=(1.96)^{2}(0.44 \times 0.56) /(0.05)^{2}=378
$$

Then adding $10 \%(378 \times 0.1=37.8)$ of non-respondent the total sample size for this study is $378+37=415$.

Similarly, to attain the second objectives, the prevalence occupied $33.5 \%$ among students consuming alcohol [16], 95\% confidence level, using a simple population formula:

$$
n^{2}=\frac{Z \alpha^{2} p(1-p)}{d^{2}}
$$

where;

$$
n=\text { is the minimum sample size required }
$$

$Z=$ standard normal distribution $(Z=1.96)$ with confidence interval of $95 \%$ and $\alpha=0.05$

$P=$ prevalence of sexual risky behavior among students consuming alcohol status hence, $P=33.5 \%$ was used [16].

$d=$ Absolute precision or tolerable margin of error $(d)=5 \%=0.05$

The following assumption was made during determining the sample size

$$
\mathrm{n}=\frac{(1.96)^{2}(0.33 \times 0.67)}{(0.05)^{2}}=339.75
$$

Then adding $5 \%(339.75 \times 0.05=16.98 \approx 17)$ of non-respondent the total sample size for the second objective is $340+17=357$.

Finally, to get the maximum sample size we have done two formulas by taking two findings from previous research. Doing all this in order to account for missing values, the higher sample size (415) was chosen.

Among 40 departments by using simple random sampling the departments was selected. And then using sampling proportional to population size the number of study participants was allocated among selected departments. From this allocated students among department using sampling frame the study unit was selected using systematic random sampling method.

\subsection{Data Collection}

Data was collected by trained persons under the supportive supervision of the investigators.

Data was collected by the structured questionnaire with the participants during a data collection time. Additionally, base line clinical information was traced from the client's record by using checklists/ data extraction format.

\subsection{Measurements}

The instrument was adapted from the Youth Risky Behavior Questionnaire (YRBQ). The youth risk behavior surveillance system was developed by the centers for disease and prevention to monitor health risk behavior that contributes 
to the leading causes of mortality, morbidity and social problems among youth and adults in the United States. The youth risk behavior surveillance system monitors six categories of behaviours: those that contribute to unintentional injuries and violence; tobacco use; alcohol and other drug use; sexual behavior that contributes to unintended pregnancy and sexually transmitted diseases; dietary behavior; and physical activity. However, the section of the scale that related to risky sexual behavior was used. The Cronbach's alpha value obtained was 0.81 . An example of items on the scale is "In the last twelve months, I have had sex with multiple partners". Religiosity was measured using the Santa Clara strength of religiosity faith questionnaire developed by [27]. It was designed to measure the impact of religion on the respondent's daily life and to determine the extent of individual participation in religious participation in ritual practices. The scale is applicable to religiosity in general. No particular religious affiliation or denominational creed is assumed. The scale was international journal of adolescence and youth 411 adapted to reflect religiosity and risky sexual behavior in adolescence. The participants were asked to respond to a four-point rating scale ranging from "strongly agree" (1) to "strongly disagree" (4), with a high score indicating a positive response or favorable response. An example of items on the scale is "I pray regularly". Cronbach's coefficient alpha values were over 90, indicating high internal consistency for the instrument. A semi structured questionnaire was used to collect socio-demographic characteristics and some clinical factors.

\subsection{Data Analysis}

Data entry was done using EPI-INFO version 3.5.3 and then exported into Statistical Package for the Social Sciences (SPSS) window version 20 for analysis. The survey data was analyzed using both descriptive statistic and econometrics analysis techniques to give empirical evidences for the basic research questions of this report and presents the results and findings of the research. Hence descriptive statistics such as percentage and frequency distribution were employed and binary logistic, econometric model was used to identify determinants of risky sexual behaviors among Jigjiga University students in Jigjiga Ethiopia, 2018. P-value less than 0.05 were considered as statistically significant. Bivariate and multivariate logistic regression analysis was conducted to identify associated factors of sexual risk behaviors with the students. The strength of the association was presented by odds ratio with $95 \%$ C.I.

\subsection{Ethical Consideration}

This study was conducted only after formal approval of the protocol was obtained from the office of research at Jigjiga University. Prior to data Collection written informed consent was obtained from the participants through detail explanation of the study and the study procedures. The right was given to the study participants to refuse or discontinue participation at any time they want and the chance to ask any thing about the study. For the purpose of anonymity 
participant's name was not be used at any time of data collection and all other personnel information kept entirely anonymous and confidentiality.

\section{Results and Discussion}

\subsection{Socio-Demographic Characteristics}

A total of 403 out of which 260 (65\%) male and 143 (35\%) female) university students participated in this study with $97 \%$ response rate. The minimum and maximum ages of the respondents were between 17 and 29 years old respectively. About 201 (49.9\%) of the respondents were Muslims, 120 (30\%) of them were orthodox Christians, 37 (9\%) of them were catholic, 24 (6\%) of them were protestant and 21 (5\%) of them were from other faiths and many more was summarized in Table 1.

\subsection{Sexual Risk Behaviors and Clinical Characteristics}

Attachment to religion, attitude and peer pressure has significant effect on sexual risk behaviors of the individual. Forty four percent (44\%) of the students

Table 1. Distribution of students by socio demographic factors at Jigjiga university students; May, $2018(\mathrm{n}=403)$.

\begin{tabular}{|c|c|c|c|}
\hline Variables & Categories & Frequencies & Percent \\
\hline \multirow[t]{4}{*}{ Age } & $0-18$ & 46 & $11.41 \%$ \\
\hline & $19-21$ & 198 & $49.14 \%$ \\
\hline & $22-25$ & 148 & $36.72 \%$ \\
\hline & $26-30$ & 11 & $2.73 \%$ \\
\hline \multirow[t]{2}{*}{ Sex } & Male & 260 & $64.52 \%$ \\
\hline & Female & 143 & $35.48 \%$ \\
\hline \multirow[t]{5}{*}{ Religion } & Muslim & 201 & $49.9 \%$ \\
\hline & Orthodox & 120 & $30 \%$ \\
\hline & Catholic & 37 & $9 \%$ \\
\hline & Protestant & 24 & $6 \%$ \\
\hline & others & 21 & $5 \%$ \\
\hline \multirow[t]{5}{*}{ Ethnicity } & Somali & 125 & $31.02 \%$ \\
\hline & Amhara & 133 & 33.00 \\
\hline & Oromo & 45 & $11.17 \%$ \\
\hline & Gurage & 72 & $17.87 \%$ \\
\hline & others & 28 & $6.95 \%$ \\
\hline \multirow[t]{5}{*}{ Class in year } & I & 29 & $7 \%$ \\
\hline & II & 104 & $15 \%$ \\
\hline & III & 169 & $52 \%$ \\
\hline & IV & 17 & $6 \%$ \\
\hline & $\mathrm{V}$ & 84 & $20 \%$ \\
\hline
\end{tabular}


engaged in sexual risk behaviors consider themselves attached to their religion. Regarding Attitude and Peer pressure towards sexual risk behaviors, students have varied with the highest percentages having good attitude but also impact of peer pressure. Students who were engaged in risk sexual behaviors were also those reported the use of different substances including tobacco, alcoholic and khat which imply the existence of relationship between uses of substances and being in risk sexual behaviors. Regarding the interpretation of the above descriptive statistics, From among 403 respondents $61.54 \%$ reported that they had used tobacco, $46.89 \%$ used alcohol and $51.36 \%$ used khat from those engaged in sexual risk behavior. The Tobacco was the most used type of substance (61\%) in the university and many more was summarized in Table 2 .

Most of the respondents had history of multiple sexual partners at the age between 19 to 21 years. Regarding the use of contraceptives and use, students who are age between 19 to 21 years reported that they used more contraceptives and condom than other age groups. The age at which respondent had their last sexual intercourse varied with the highest percentages being between 19 to 21 years who engaged in risk sexual behavior. The prevalence of multiple sex partners over the last 12 months among the age between 19 to 21 years was higher than other age groups. So in general we can conclude from under mentioned table that the most crucial age for the students engaged in sexual risk behavior was between 19 to 21 years (hot age) Table 3.

\subsection{Factors Associated with Sexual Risk Behaviors}

In the preceding parts of this paper the descriptive analysis and univariate analysis of important explanatory variables, which are expected to have impact on sexual risk behaviors of Students were presented. In this section, selected explanatory variables were used to estimate the logistic regression model to analyze the determinants of Students sexual risk behaviors. A logit model was fitted to estimate the effects of the hypothesized explanatory variables on the probabilities of being in risky sexual behaviors or not. SPSS 20 was used for the econometrics analysis. Prior to the estimation of the model parameters, it is crucial to look into the problem of multi-co linearity or association among the potential candidate variables. To this end, the contingency coefficient was used to test the degree of multi-co linearity among the variables.

The various goodness of-fit measures validate that the model fits the data well. The likelihood ratio test statistics exceeds the Chi-square critical value with 14 degree of freedom at less than $1 \%$ level of significance, indicating that the hypothesis that all coefficients except the intercept are equal to zero is rejected. The value of Pearson Chi-square test shows the overall goodness of-fit of the model at less than $1 \%$ probability level and many more was summarized in Table 4.

\subsection{Explanation of Significant from Selected Socio-Demographic Independent Variables}

Five selected socio-demographic independent variables that are hypothesized to 
have influence on sexual risk behaviors in the study area were included in the model, of which four were found to be statistically significant even though the level of statistical significance for the independent variables included in the

Table 2. Distribution of students by factors related risky sexual behaviors at Jigjiga university; students May, $2018(\mathrm{n}=403)$.

\begin{tabular}{|c|c|c|c|}
\hline Variables & Categories & Frequencies & Percent \\
\hline \multirow[t]{4}{*}{ Active in my faith/religion } & Strongly Agree & 181 & $44.91 \%$ \\
\hline & Agree & 134 & $33.25 \%$ \\
\hline & Disagree & 58 & $14.39 \%$ \\
\hline & Strongly Disagree & 30 & $7.44 \%$ \\
\hline \multirow[t]{2}{*}{ Attitude } & Good & 208 & $51.61 \%$ \\
\hline & Not Good & 195 & $48.39 \%$ \\
\hline \multirow[t]{2}{*}{ Peer pressure } & Yes & 203 & $50.37 \%$ \\
\hline & No & 200 & $49.63 \%$ \\
\hline \multirow[t]{2}{*}{ Contraceptive use } & Yes & 211 & $47.64 \%$ \\
\hline & No & 192 & $52.36 \%$ \\
\hline \multirow[t]{2}{*}{ Condom use } & Yes & 211 & $47.64 \%$ \\
\hline & No & 192 & $52.36 \%$ \\
\hline \multirow[t]{2}{*}{ Unwanted pregnancy } & Yes & 240 & $59.55 \%$ \\
\hline & No & 163 & $40.45 \%$ \\
\hline \multirow[t]{3}{*}{ Had sex last time } & sone month & 107 & $26.55 \%$ \\
\hline & 1 to 3 months & 203 & $50.37 \%$ \\
\hline & $\geq 3$ months & 93 & $23.08 \%$ \\
\hline \multirow{5}{*}{$\begin{array}{l}\text { Sex partners in the past } \\
12 \text { months }\end{array}$} & One & 129 & $32.01 \%$ \\
\hline & Two & 66 & $16.38 \%$ \\
\hline & Three & 48 & $11.91 \%$ \\
\hline & Four & 80 & $19.85 \%$ \\
\hline & $\geq$ five & 80 & $19.85 \%$ \\
\hline \multirow[t]{4}{*}{ Sex Partner Age } & $0-19$ & 96 & $23.82 \%$ \\
\hline & $20-30$ & 191 & $47.39 \%$ \\
\hline & $31-40$ & 94 & $23.33 \%$ \\
\hline & above 40 & 22 & $5.46 \%$ \\
\hline \multirow[t]{2}{*}{ Tobacco } & Yes & 248 & $61.54 \%$ \\
\hline & No & 155 & $38.46 \%$ \\
\hline \multirow[t]{2}{*}{ Alcohol } & Yes & 189 & $46.89 \%$ \\
\hline & No & 214 & $53.11 \%$ \\
\hline \multirow[t]{2}{*}{ khat } & Yes & 207 & $51.36 \%$ \\
\hline & No & 196 & $48.64 \%$ \\
\hline
\end{tabular}


Table 3. Describes sexual risk behaviors variables: contraceptive, condom use, unwanted pregnancy, last time you had sex and number \& age of sexual partner in perspective to age at Jigjiga university; students May, $2018(n=403)$.

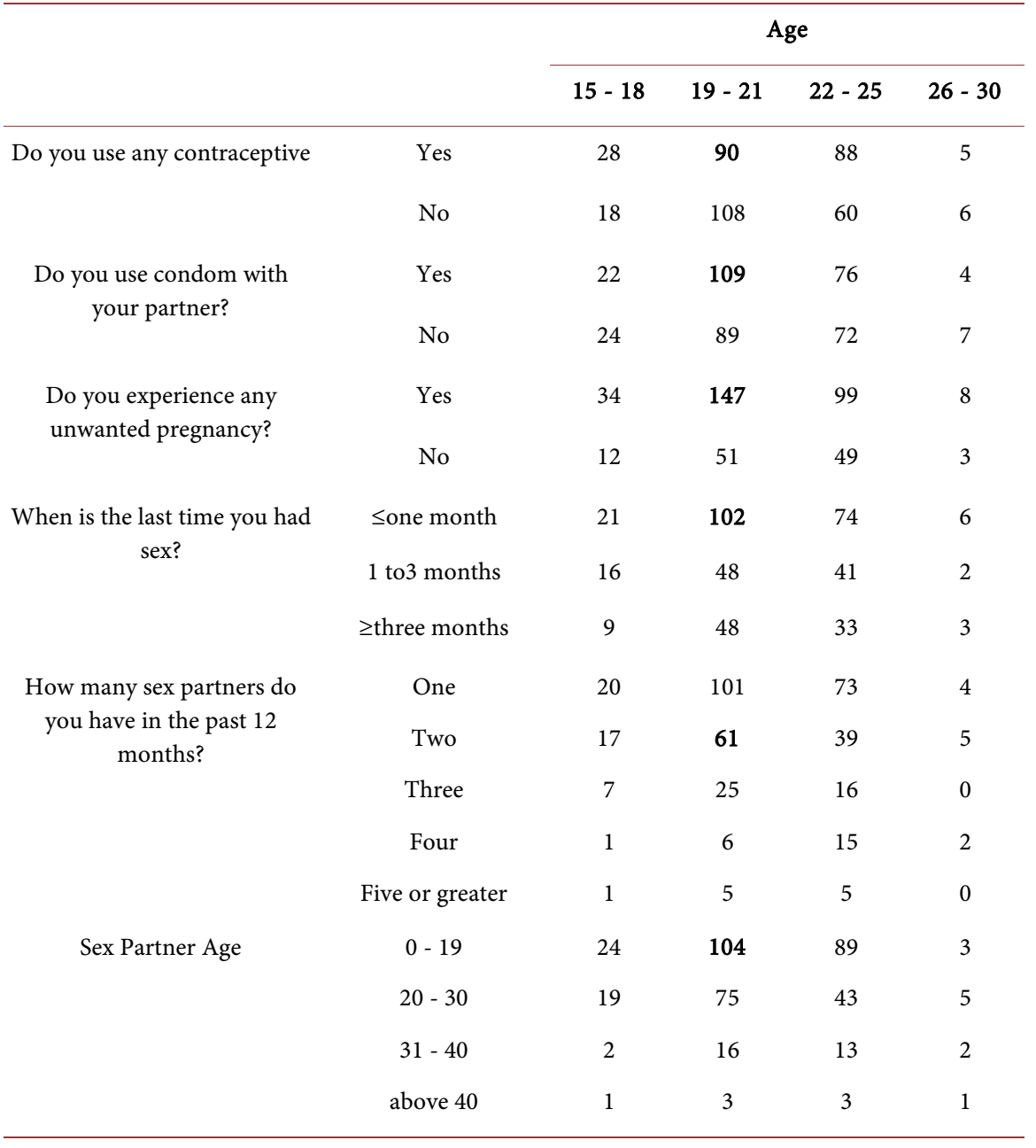

model was different for individual variable and the sign of the significant parameters were as expected. The model output revealed that Age, Religion, ethnicity and class in years were significant at less than one percent probability level.

\subsection{Factors Associated Risky Sexual Behavior}

On Bivariate logistic regression, variables including: age, sex, active in my faith/religion, contraceptive use, condom use, unwanted pregnancy, had sex last time, sex partners in the past 12 months, sex partner age, attitude, peer pressure, tobacco, alcohol and chat use were found to have statistically association with the outcome variable and for further analysis entered in to multivariate logistic analysis. On the other hand religion, ethnicity and class in year were not associated at 0.25 level of significance and were excluded from further analysis.

During the multivariate analysis of risky sexual behavior in relation to all explanatory variables; age, active in my faith/religion, contraceptive use, condom use, peer pressure, tobacco and alcohol were found to be statistically significant. 


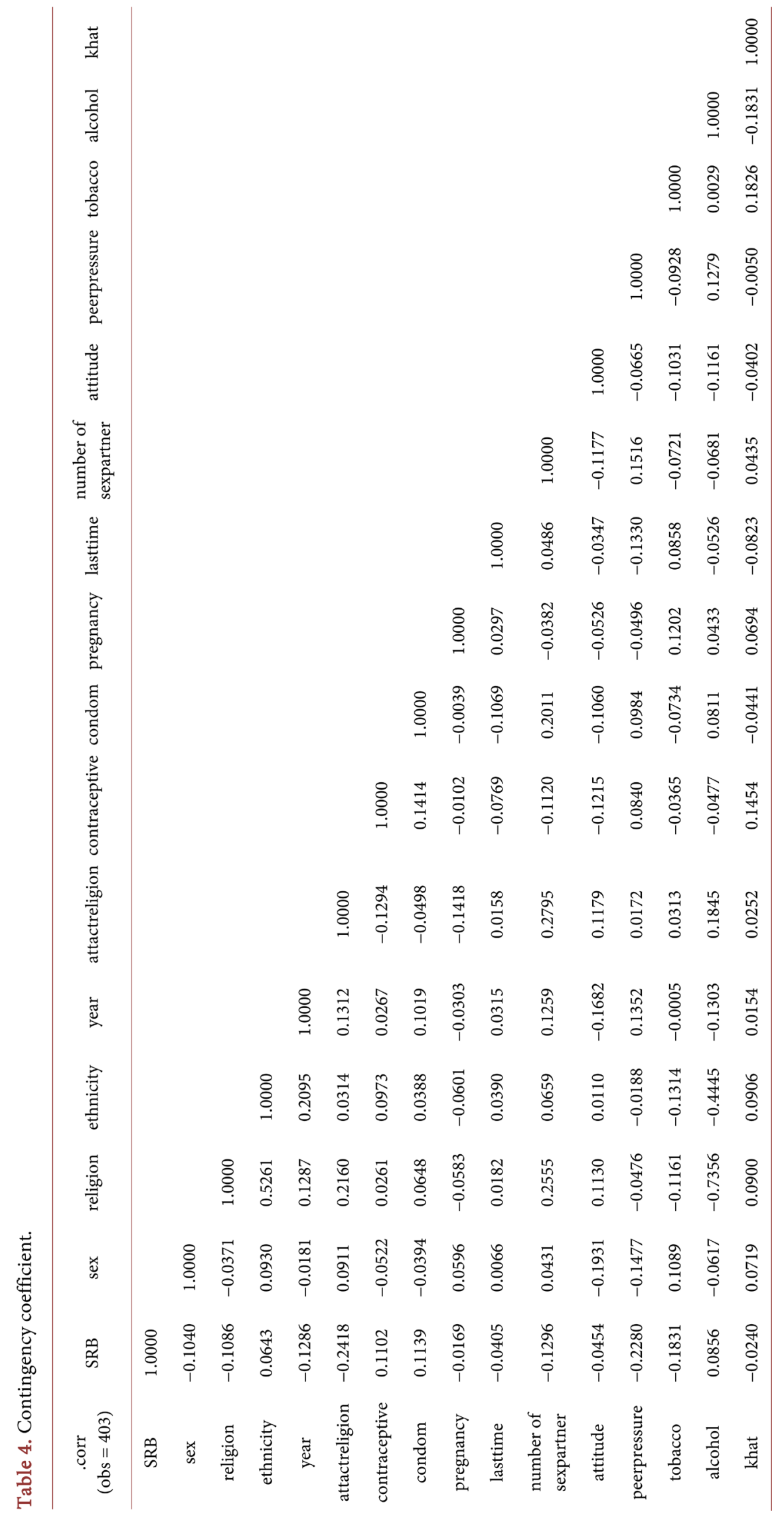


Study participants whose age is 19 - 21 years were about three times more likely to be risky sexual behavior as compared with the other age group [AOR $=3.82$, $95 \% \mathrm{CI},(2.28,9.41)]$. Students who didn't believe in practicing their religion actively were about four times more likely to be risky sexual behavior as compared with students who had believe strongly in practicing their religion $[\mathrm{AOR}=3.68$, 95\% CI, $(1.344,10.115)]$.

Concerning contraceptive use among study participants, students who didn't had used different methods of contraceptive were about six times more likely to be risky sexual behavior when compared to students who had used contraceptives $[\mathrm{AOR}=6.38,95 \% \mathrm{CI}(3.96,10.27)]$. In another way who hadn't used condom among study participants, were about six times more likely to be risky sexual behavior as compared to students who had used condom $[\mathrm{AOR}=6.38,95 \%$ CI $(3.96,10.27)]$.

Students who had peer pressure were about fourteen times more likely to be engaged in risky sexual behavior as compared with study participants who didn't had pressure in their friends [AOR $=14.52,95 \%$ CI $(4.702,44.891)]$. Regarding substance use patients who were using tobacco were found to be three times more likely to be engaged in risky sexual behavior than students who didn't use tobacco and having history of alcohol consumption were two times more likely to be engaged in risky sexual behavior $[\mathrm{AOR}=3.191,95 \% \mathrm{CI}(1.83,5.54)]$ and $1.64,95 \%$ CI $(1.39,2.06)]$ respectively (Table 5$)$.

Table 5. Multivariate logistic regression analysis of associated factors for Risky Sexual Behaviors among Jigjiga university students; May, $2018(\mathrm{n}=403)$.

\begin{tabular}{|c|c|c|c|c|}
\hline \multirow{2}{*}{$\begin{array}{c}\text { Explanatory } \\
\text { variables }\end{array}$} & \multicolumn{3}{|c|}{ frequency Risky Sexual Behavior } & \multirow{2}{*}{ AOR $(95 \% \mathrm{CI})$} \\
\hline & N (\%) & Yes & No & \\
\hline \multicolumn{5}{|l|}{ Age } \\
\hline $0-18$ & $46(11.41 \%)$ & $26(11 \%)$ & $20(12 \%)$ & $13.60(0.91,2.43)$ \\
\hline $19-21$ & $198(49.14 \%)$ & $105(44 \%)$ & $93(57 \%)$ & $3.82(2.28,9.41)^{* *}$ \\
\hline $22-25$ & $148(36.72 \%)$ & $100(42 \%)$ & $48(29 \%)$ & $3.21(0.93,11.02)$ \\
\hline $26-30^{(\mathrm{R})}$ & $11(2.73 \%)$ & $9(4 \%)$ & $2(1 \%)$ & 1.00 \\
\hline \multicolumn{5}{|l|}{ Sex } \\
\hline Male & $260(64.52 \%)$ & $145(60 \%)$ & $115(71 \%)$ & $1.41(0.647,2.01)$ \\
\hline Female $^{(\mathrm{R})}$ & $143(35.48 \%)$ & $95(40 \%)$ & $48(29 \%)$ & 1.00 \\
\hline \multicolumn{5}{|c|}{ Active in my Faith/Religion } \\
\hline Strongly Agree ${ }^{(\mathrm{R})}$ & $181(44.91)$ & $95(40 \%)$ & $86(53 \%)$ & 1.00 \\
\hline Agree & $134(33.25 \%)$ & $66(28 \%)$ & $68(42 \%)$ & $3.174(5.204,8.368)$ \\
\hline Disagree & $58(14.39 \%)$ & $56(23 \%)$ & $2(1 \%)$ & $3.687(1.344,10.115)^{* *}$ \\
\hline Strongly Disagree & $30(7.44 \%)$ & $23(10 \%)$ & $7(4 \%)$ & $0.086(0.015,0.485)$ \\
\hline \multicolumn{5}{|l|}{ Contraceptive use } \\
\hline $\mathrm{Yes}^{(\mathrm{R})}$ & $211(47.64 \%)$ & $59(28.92 \%)$ & $152(76.38 \%)$ & 1.00 \\
\hline
\end{tabular}




\section{Continued}

\begin{tabular}{|c|c|c|c|c|}
\hline No & $192(52.36 \%)$ & $145(71.08 \%)$ & $47(23.62 \%)$ & $6.38(3.96,10.27)^{* *}$ \\
\hline \multicolumn{5}{|l|}{ Condom use } \\
\hline $\mathrm{Yes}^{(\mathrm{R})}$ & $211(47.64 \%)$ & $59(28.92 \%)$ & $152(76.38 \%)$ & 1.00 \\
\hline No & $192(52.36 \%)$ & $145(71.08 \%)$ & $47(23.62 \%)$ & $6.38(3.96,10.27)^{\star *}$ \\
\hline \multicolumn{5}{|c|}{ Unwanted Pregnancy } \\
\hline Yes & $240(59.55 \%) 2$ & $200(69.44 \%)$ & $40(34.78 \%)$ & $10.89(11.47,18.32)$ \\
\hline $\mathrm{No}^{(\mathrm{R})}$ & $163(40.45 \%)$ & $88(30.56 \%)$ & $75(65.22 \%)$ & 1.00 \\
\hline \multicolumn{5}{|c|}{ Had sex last time } \\
\hline sone month & $107(26.55 \%)$ & $65(60.75 \%)$ & $42(39.25 \%)$ & $1.270(0.710,2.272)$ \\
\hline 1 to 3 months & $203(50.37 \%)$ & $115(56.65 \%)$ & $88(43.35 \%)$ & $1.415(0.728,2.752)$ \\
\hline$\geq 3$ months $^{(\mathrm{R})}$ & $93(23.08 \%)$ & $26(27.96 \%)$ & $67(72.04 \%)$ & 1.00 \\
\hline \multicolumn{5}{|c|}{ Sex partners in the past 12 months } \\
\hline one $e^{(\mathrm{R})}$ & $129(32.01 \%)$ & $7(3.48 \%)$ & $122(60.4 \%)$ & 1.00 \\
\hline two & $66(16.38 \%)$ & $16(7.96 \%)$ & $50(24.75 \%)$ & $1.392(0.320,6.056)$ \\
\hline three & $48(11.91 \%)$ & $30(14.93 \%)$ & $18(8.91 \%)$ & $1.774(0.396,7.941)$ \\
\hline four & $80(19.85 \%)$ & $72(35.82 \%)$ & $8(3.96 \%)$ & $2.141(0.427,10.732)$ \\
\hline$\geq$ five & $80(19.85 \%)$ & $76(37.81)$ & $4(1.98 \%)$ & $1.577(0.279,8.898)$ \\
\hline \multicolumn{5}{|c|}{ Sex Partner Age } \\
\hline $0-19$ & $96(23.82 \%)$ & $33(12.59 \%)$ & $63(44.68 \%)$ & $1.021(0.983,1.060)$ \\
\hline $20-30$ & $191(47.39 \%)$ & $133(50.76 \%)$ & $58(41.13 \%)$ & $2.021(0.983,1.040)$ \\
\hline $31-40$ & $94(23.33 \%)$ & $90(34.35 \%)$ & $4(2.84 \%)$ & $0.021(0.983,1.050)$ \\
\hline above 40 & $22(5.46 \%)$ & $6(2.29 \%)$ & $16(11.35 \%)$ & 1.00 \\
\hline \multicolumn{5}{|l|}{ Attitude } \\
\hline $\operatorname{Good}^{(\mathrm{R})}$ & $208(51.61 \%)$ & $121(50 \%)$ & $87(53 \%)$ & 1.00 \\
\hline Not Good & $195(48.39 \%)$ & $119(50 \%)$ & $76(47 \%)$ & $0.80(0.497,1.302)$ \\
\hline \multicolumn{5}{|l|}{ Peer pressure } \\
\hline Yes & $203(50.37 \%)$ & $199(83 \%)$ & $4(2 \%)$ & $14.52(4.702,44.891)^{* *}$ \\
\hline $\mathrm{No}^{(\mathrm{R})}$ & $200(49.63 \%)$ & $41(17 \%)$ & $159(98 \%)$ & 1.00 \\
\hline \multicolumn{5}{|l|}{ Tobacco } \\
\hline Yes & $248(61.54 \%)$ & $175(73 \%)$ & $73(45 \%)$ & $3.191(1.83,5.54)^{* *}$ \\
\hline $\mathrm{No}^{(\mathrm{R})}$ & $155(38.46 \%)$ & $65(27 \%)$ & $90(55 \%)$ & 1.00 \\
\hline \multicolumn{5}{|l|}{ Alcohol } \\
\hline Yes & $189(46.89 \%)$ & $121(50 \%)$ & $68(42 \%)$ & $1.64(1.39,2.06)^{* *}$ \\
\hline $\mathrm{No}^{(\mathrm{R})}$ & $214(53.11 \%)$ & $119(50 \%)$ & $95(58 \%)$ & 1.00 \\
\hline \multicolumn{5}{|l|}{ khat } \\
\hline Yes & $207(51.36 \%)$ & $160(67 \%)$ & $47(29 \%)$ & $0.885(0.519,1.510)$ \\
\hline $\mathrm{No}^{(\mathrm{R})}$ & $196(48.64 \%)$ & $80(33 \%)$ & $116(71.16 \%)$ & 1.00 \\
\hline
\end{tabular}




\section{Conclusion and Recommendations}

The study revealed that being too young in terms of age, not active in faith/religion, lack of contraceptive method, not using condom, peer pressure, tobacco use and drinking alcohol were factors in the study that can lead youths to engage in risky sexual behaviors.

According to the findings of this study, efforts regarding minimizing factors influencing sexual risk behaviors should be directed more towards parents and peers than educators. This view is captured more in the following sub-recommendations: direct public education initiatives that increase recognition and understanding of the importance of parent-youth relationship through advertisement by media and through provision of information brochures in government agencies, public health offices and schools should be encouraged and promoted. Youths should closely follow religious institutions and should also have close parental control to minimize those factors influencing risky sexual behaviors. Education on reproductive and sexual health with emphasis on the consequences of all the aforementioned risk behaviors, including the negative impacts of peer pressure, should be included in the delivery massages and strategies for tackling those factors influencing sexual risk behaviors. Future researchers should address issues on factors, specifically youths' attachment to religion, age, lack of contraceptive method, not using condom, peer pressure, tobacco use and drinking alcohol as one point of intervention to reduce youths' sexual risk behaviors. Further investigation with particular emphasis on establishing the temporal relationship using longitudinal study designs must be undertaken.

This study can be significant to different age groups specifically; the adolescents and teenagers through designing programs can be useful in providing reproductive health information as part of programs that focus on the general well-being of the participants. Programs to improve teenagers' reproductive health must understand these risks and consider the many influences on teenagers' lives. Such factors as whether adolescents have initiated sexual activity, are married, are in school, or are working, are important. The impact of poverty, gender inequities, legal restrictions, and cultural barriers must also be addressed. Successful programs should provide necessary counseling and clinical services and aim to help young people develop skills to make healthy life choices. These programs should respect the needs, concerns, and insights of young people by including them in the design and implementation of activities. Successful programs also should work with parents' community groups and religious leaders to secure their acceptance.

\section{Acknowledgements}

We would like to express our gratitude to data collectors, supervisors and study participants for their preciseness and commitment in the collecting and inputting high quality data used in the study. 


\section{Availability of Data and Materials}

The datasets used and/or analyzed during the current study are available from the corresponding author on reasonable request.

\section{Authors' Contributions}

JKM and KM had taken a principal role in the conception of ideas, developing methodologies, data collection, analyses and write up of the article. JKM and KM participate in data analysis and had a great contribution to the write up of the draft and approval of the final version of the manuscript. All authors read and approved the final manuscript.

\section{Conflicts of Interest}

The authors declare no conflicts of interest regarding the publication of this paper.

\section{References}

[1] WHO (2006) Investing in Our Future: A Framework for Accelerating Action for the Sexual and Reproductive Health of the Young People. Geneva.

[2] Linbee, S., Valencia, B.S. and Cromer, B.A. (2000) Sexual Activity and Other High-Risk Behaviors in Adolescents with Chronic Illness: A Review. Journal of Pediatrics and Adolescence, 13, 53-64. https://doi.org/10.1016/S1083-3188(00)00004-8

[3] Joint United Nation Program on HIV/AIDS (2005) Aids Epidemic Updates.

[4] Federal HIV/AIDS Prevention and Control Office (FHAPCO) (2008) Federal Democratic Republic of Ethiopia. Reports on Progress towards Implementation of the UN Declaration of Commitment on HIV/AIDS, Addis Ababa, Ethiopia.

[5] WHO (2009) Global Health: Mortality and Burden of Disease Attributable to Selected Major Risks. Author, Geneva.

[6] UNICEF, UNAIDS, WHO (2002) Young People and HIV/AIDS, Opportunity in Crisis. Population Services International Research Division, Washington DC. http://www.unicef.org/publications/files/pub_youngpeople_hivaids_en_pdf

[7] Merson, M. (1993) Discrimination against HIV Infected People or People with AIDS. WHO/GPT Speech to Commission on Human Rights, Geneva.

[8] Taffa, N. (1998) Sexuality of School Youth and Their Knowledge about STDs and HIV/ AIDS in Southeren Ethiopia. Ethiopian Journal of Health Development, 12, $17-24$.

[9] Tefera, B., Challi, J. and Yoseph, M. (2004) Knowledge, Attitude and Practice about HIV/AIDS, Voluntary Counseling and Testing among Students of Jimma University, Jimma Zone, Southwest Ethiopia. Ethiopian Journal of Health Sciences, 10, 43-53.

[10] Whiteside, et al. (2001) Risks and Adverse Outcomes of Sexually Transmitted Diseases: Patients' Attitudes and Beliefs. Journal of Reproductive Medicine, 46, 34-38.

[11] UNSECO (2000) Promoting Population and Reproductive Health, Especially among Young People, through Basic Education: Issues Paper Strategy Session III. 2. http://www.unesco.org/education/wef/en-conf/coverage_sessionIII_2.shtm

[12] Arvanitidou, et al. (2008) Cigarette Smoking among Adolescents in Thessaloniki, Greece. International Journal of Public Health, 53, 204-207. https://doi.org/10.1007/s00038-008-8001-5 
[13] Roskin, J. and Aveyard, P. (2009) Canadian and English Students' Beliefs about Waterpipe Smoking: A Qualitative Study. BMC Public Health, 9, Article No. 10. https://doi.org/10.1186/1471-2458-9-10

[14] O'Connor, N., O'Connor, M. and Bradley, C. (2008) Alcohol-How Much Is Too Much? Irish Medical Journal, 101, 200-202.

[15] Brar, A. and Moneta, G. (2009) Negative Emotions and Alcohol Dependence Symptoms in British Indian and White College Students. Addictive Behavior, 34, 292-296. https://doi.org/10.1016/j.addbeh.2008.11.018

[16] Salameh, P., Jomaa, L., Issa, C., et al. (2014) Assessment of Health Risk Behaviours among University Students: A Cross-Sectional Study in Lebanon. International Journal of Adolescence and Youth, 19, 203-216. https://doi.org/10.1080/02673843.2012.733313

[17] Ndumiso, D.N., Sibusiso, M. and Thobile, Z. (2016) Qualitative Evaluation of Selected Social Factors That Impact Sexual Risk-Taking Behaviour among African Students in Kwazulu Natal, South Africa. SAHARA-J: Journal of Social Aspects of HIVI AIDS, 13, 96-105. https://doi.org/10.1080/17290376.2016.1218792

[18] McNair, L., Carter, J. and Williams, M. (1998) Self-Esteem, Gender, and Alcohol Use: Relationships with HIV Risk Perception and Behaviors in College Students. Journal of Sex and Marital Therapy, 24, 29-36. https://doi.org/10.1080/00926239808414666

[19] Hagenhoff, C., Lowe, A., Hovell, M. and Rugg, D. (1997) Prevention of the Teenage Pregnancy Epidemic: A Social Learning Theory Approach. Education and Treatment of Children, 10, 67-83.

[20] Langer, L.M., Warheit, G.J. and McDonald, L.P (2001) Correlates and Predictors of Risky Sexual Practices among a Multi-Racial/Ethnic Sample of University Students. Social Behaviour, 29, 133-144. https://doi.org/10.2224/sbp.2001.29.2.133

[21] Smith, C. (2001) Adolescents and Loss of Self-Esteem among Undergraduate Student in Selected Schools in Delta State. Understanding Adolescent Psychology. Whyte and Whyte Publishers, Owerri.

[22] Ugoji, F.N. (2014) Determinants of Risky Sexual Behaviours among Secondary School Students in Delta State Nigeria. International Journal of Adolescence and Youth, 19, 408-418. https://doi.org/10.1080/02673843.2012.751040

[23] Henok, A., Kassa, A., Lenda, A., et al. (2015) Knowledge, Attitude and Practice of Risky Sexual Behavior and Condom Utilization among Regular Students of Mizan-Tepi University, South West Ethiopia. Journal of Child and Adolescent Behavior, 3,5 .

[24] Mengistu, T.S., Melku, A.T., Bedada, N.D. and Eticha, B.T. (2013) Risks for STIs/HIV Infection among Madawalabu University Students, Southeast Ethiopia: A Cross Sectional Study. Reproductive Health, 10, 38. https://doi.org/10.1186/1742-4755-10-38

[25] Dingeta, T., Oljira, L. and Assefa, N. (2012) Patterns of Sexual Risk Behavior among Undergraduate University Students in Ethiopia: A Cross-Sectional Study. The Pan African Medical Journal, 12, 33.

[26] USAID (2008) Central Statistical Agency, Addis Ababa.

[27] Plante, T.G. and Boccaccini, M. (1997) The Santa Clara Strength of Religious Faith Questionnaire. Pastoral Psychology, 45, 375-387.

https://doi.org/10.1007/BF02230993 


\section{List of Abbreviation}

$\begin{array}{ll}\text { CI } & \text { Confidence Interval } \\ \text { HIV } & \text { Human immuno-deficiency virus } \\ \text { MARPS } & \text { Most at Risk Population Segments } \\ \text { MOE } & \text { Ministry of education } \\ \text { MOH } & \text { Ministry of health } \\ \text { SPSS } & \text { Statistical Package for the Social Sciences } \\ \text { STIs } & \text { Sexually Transmitted Infections } \\ \text { STDs } & \text { Sexually Transmitted Diseases } \\ \text { WHO } & \text { World Health Organization } \\ \text { YRBQ } & \text { Youth Risky Behavior Questionnaire }\end{array}$

